\title{
Market Knowledge and Stakeholder Considerations for the Biopharmaceutics Sector-Incorporating User Value and Societal Needs in Therapeutic Interventions
}

\author{
James K. Timmis ${ }^{1,2 *}$, Raymond X. Van Der Waal' ${ }^{1}$ Jennifer Herz ${ }^{3}$, Mark B. Van Der Waal', \\ Eric Claassen ${ }^{1}$, Linda H. M. Van De Burgwal1 \\ ${ }^{1}$ Athena Institute for Research on Innovation and Communication in Health and Life Sciences, Vrije Universiteit Amsterdam, \\ Amsterdam, The Netherlands \\ ${ }^{2}$ Institute for Nursing Science, Faculty of Medicine, University of Freiburg, Freiburg, Germany \\ ${ }^{3}$ Biointelect, Sydney, Australia \\ Email: *james.timmis@uniklinik-freiburg.de
}

How to cite this paper: Timmis, J.K., Van Der Waal, R.X., Herz, J., Van Der Waal, M.B., Claassen, E. and Van De Burgwal, L.H.M. (2021) Market Knowledge and Stakeholder Considerations for the Biopharmaceutics Sector-Incorporating User Value and Societal Needs in Therapeutic Interventions. Health, 13, 1365-1395.

https://doi.org/10.4236/health.2021.1311099

Received: October 13, 2021

Accepted: November 27, 2021

Published: November 30, 2021

Copyright $\odot 2021$ by author(s) and Scientific Research Publishing Inc. This work is licensed under the Creative Commons Attribution International License (CC BY 4.0).

http://creativecommons.org/licenses/by/4.0/

\section{(c) (i) Open Access}

\begin{abstract}
Purpose: Many health systems are considered ill-equipped to adequately meet future demand. Although academic entrepreneurs and small and medium-sized enterprises (SMEs) drive health technology innovation, they often suboptimally consider important market and stakeholder requirements. This can result in missed opportunities to improve health system performance, address demand-supply gaps, and achieve financial rewards. Market intelligence can provide crucial information in this regard, but scientifically sourced guidance on how to perform market research for biopharmaceutics is scarce. Our objective was, therefore, to create and provide an easily accessible biopharmaceutics market research toolbox that can be perused by academic entrepreneurs and SMEs to improve the alignment of their developments with stakeholder needs. Design: Guided by market orientation theory, we interviewed senior managers and commercialisation experts from the biopharmaceutics sector. We asked them which information they consider most relevant, and how they collect, analyse and respond to new information to align product features, positioning and stakeholder-relationship management with market needs. Findings: Our innovator toolbox consists of a high-level overview of market intelligence considerations mapped against a novel innovation framework, a stakeholder reasoning and value model, and detailed considerations (checklists) per stakeholder of biopharmaceutics interventions. Originality: We provide here the first market orientation-based overview of mar-
\end{abstract}


ket intelligence considerations for the biopharmaceutics sector. Although primarily collated for academic entrepreneurs and SMEs, our innovator toolbox for the biopharmaceutics sector can help all stakeholders better understand their orientation towards markets.

\section{Keywords}

Healthcare, Biopharmaceutic, Market Orientation, Market Research, Unmet Need

\section{Introduction}

Recent studies conclude that healthcare utilization, including the demand for complex and expensive interventions, will increase dramatically in the near to mid-term future [1] [2] [3] [4]. New health technologies offer significant potential for addressing previously untreatable disorders, and more effectively and efficiently managing complex conditions. They also allow disinvestment of less cost-effective interventions and, in turn, contribute to meeting increased and hitherto unmet demand for healthcare [5] [6].

Academic entrepreneurs and small and medium-sized enterprises (SMEs; henceforth: innovators) in the biopharmaceutics sector are major repositories of new health technologies [7]. However, the development of new interventions in the heavily regulated healthcare sector is associated with high cost and risk of failure- 9 of 10 potential new interventions do not reach the market [8]. In addition to technical risk, one important factor that contributes to product failures is the suboptimal appreciation and utilization of market intelligence (MI). For various reasons, SMEs tend to underinvest in identifying the requirements of their (prospective) market(s) [7] [9]. A British Academy of Management report (2014) cites a variety of barriers for the utilization of MI by SMEs, such as lack of 1) financial resources, 2) market information, 3) human resources, 4) time, and 5) marketing expertise [10]. Subsequently, innovators might not have access to, or sufficient expertise to proficiently analyze, MI; not be aware that their information is incomplete; due to their value judgements dismiss relevant vignettes, or underestimate MI's utility for commercialization success [11] [12] [13] [14]. Not judiciously considering MI at the earliest development stage possible can inter alia frustrate efforts to secure funding for crucial development activities, or considerably delay and/or prevent market entry [7]. Indeed, failure of various stakeholders to maximize the potential of new health technologies can lead to unnecessarily foregone opportunities to adequately address unmet (societal/medical) needs [15] [16] [17].

To provide a more holistic approach to addressing these issues, a recent study systematically reviewed the extant literature relating to innovation frameworks and identified a plethora of factors that can accelerate science-based innovation and knowledge valorization, i.e. the translation of academic knowledge into 
products, services, etc., that create societal value [18]. These factors were stratified across 4 overarching domains and are illustrated in the Societal Impact Value Cycle (SIVC, see Appendix 1). The SIVC was designed to help stakeholders relate their activities to those of others and the steps to consider in their developments [15]. However, due to its broad scope, guidance regarding market research has not been incorporated as of yet.

In this contribution, we provide innovators and policymakers with the findings of our qualitative study of MI considerations pertinent to the biopharmaceutics sector, including methods of their elicitation and examples of product improvement responses. Our results are presented as an innovator toolbox consisting of a high-level overview map (based on the SIVC), a decision pathway model to trace stakeholder reasoning and value, and detailed MI considerations (checklists) per stakeholder, see Appendixes 5-9.

\section{Methods}

\subsection{Theory}

Our study utilises a solid theoretical foundation: market orientation (MO) theory [19]. MO focusses on determinants and processes of the successful implementation of marketing, and how these activities are coordinated and used across entire organisations: “[...] [MO] is the organization wide generation of MI [market intelligence] pertaining to current and future customer needs, dissemination of the intelligence across departments, and organization wide responsiveness to it." ([19]: p. 6) MO was first popularised by Kohli \& Jaworski in 1990 and has been repeatedly, and recently, associated with positive performance of new products [20] [21] [22] [23] and entire organisations, also in the healthcare-pertinent pharmaceutical, [24], biotech [25] and food industries [26]. For more detail regarding the study-relevant components of MO, see Appendix 12.

\subsection{Data Collection}

\subsubsection{Sample}

Our purposive sample consisted of industry experts who 1) were senior managers or leaders in the biopharmaceutics industry, 2) had a commercial or marketing background, and 3) had led the introduction of at least one successful biopharmaceutic intervention (according to regulatory therapeutic registers, see below). Potential respondents were identified via the Australian biotech association's (AusBiotech) member directory, the BIO World Congress 2017 attendant list, press releases from Australian Life Sciences-related Venture Capital funds, the European EMA's and U.S. FDA's therapeutic registers, or were members of the authors' networks. JH, a biopharmaceutics commercialisation expert, provided support in assessing the adequacy of interview candidates. We first approached individuals identified through the sources above, and later expanded our sample by interviewee referral. By selecting individuals from a range of biopharmaceutics companies, and sizes thereof, we increased the diversity of our 
sample.

\subsubsection{Instrument: Semi-Structured Interviews}

To render each interview as consistent, repeatable and replicable as possible and support the quality of data collection, we performed all interviews utilising the identical interview guide [27], see Appendix 2. Questions for the interview guide were based on core MI concepts of the MO-framework, i.e. generation, dissemination and responsiveness to MI. However, since collection and analysis of MI is not, or is suboptimally, executed by innovators, questions focussed on MI generation. Follow-up questions were used to explore comments that merited further investigation. The guideline structure was as follows (and is shown in detail in Appendix 2):

- Opening: demographics (2 questions);

- MI generation (7 questions +14 probes);

- MI dissemination (1 question);

- MI responsiveness (1 question);

- Closing: comments and snowballing (2 questions).

To enhance face and content validity of the interviews, test if the questions were pertinent to our subject and sample, and improve comprehension, two health technology commercialisation experts reviewed the interview guide. In addition, two pilot interviews were performed to improve the construct validity and reliability of the interview guide, and elicit suggestions on improving the guide. The interview guide was adapted accordingly.

\subsection{Data Analysis}

To improve the validity of our study, we continued interviewing until we reached data saturation. If no new concepts were mentioned in two consecutive interviews, we considered saturation to have been achieved [28] [29]. Following the recording and transcription of interviews, a summary was shared with the interviewee, for their review (member-check). This helped us verify if we had correctly interpreted their elaborations and, thereby, improve the reliability of our analysis [30].

Analysis was performed by the first and second authors. Interview transcripts were evaluated using thematic analysis, which provides for a structured approach to extract and cluster data from textual evidence [31] [32] [33]. Analysis involved the following steps: creation of initial codes based on the MO framework, familiarisation with the data and assigning codes to text passages we deemed relevant, (sub-)theme review, summary and refinement of themes (3 iterations), and report production. In total, 21 codes were used to identify relevant passages in our data. We used computer-assisted qualitative data analysis software (Atlas.ti, version 8.4.4) to assign codes and export data in a tabular format. We then summarised similar extracts of text and grouped them into sub-themes and repeated the process until we had identified top-level themes. 


\section{Results}

\subsection{Sample}

In June 2017, we invited 80 individuals via email. 16 responded and offered to participate. From 21 June to 1 August 2017, 14 interviews (duration: $45 \mathrm{mi}$ nutes) were conducted face-to-face $(n=2)$, or by phone $(n=12)$. All respondents permitted us to record the interviews. The participation rate was $17.5 \%$. Eight participants were associated with SMEs ( 5 pharma, 3 biotech), five with Big Pharma, and one with a service provider (consultancy). All participants were, or recently had been senior managers, vice-presidents or chief-operating officers and had extensive experience ( 29 years) in marketing and/or R\&D. Central data about our interviewees are shown in Table 1, and Appendix 3. Data saturation (86 unique concepts, see Appendix 4) was achieved by the end of the 12th interview, see Figure 1. Two further control interviews were conducted but no further concepts identified.

\subsection{Analysis}

After concluding thematic analysis, we stratified our findings by stakeholder. Subsequently, we re-clustered, visualised and discussed our data several times. During this iterative analysis stage, we identified overarching themes, which we

Table 1. Central characteristics interviewees.

\begin{tabular}{cccccc}
\hline$\#$ & Sex & Job title & Country & Experience & Type of organisation \\
\hline 1 & Male & Director & AU & 45 years & Biotech SME \\
2 & Male & Head of BD & AU & 35 years & Big Pharma \\
3 & Male & Sr. Dir. Commercial & US & 30 years & Biotech SME \\
4 & Male & CEO & AU & 30 years & Biotech SME \\
5 & Male & Ex. Chairman & AU & 35 years & Biotech SME \\
6 & Male & Chief Commercial & SG & 30 years & Big Pharma \\
7 & Male & CSO & AU & 20 years & Big Pharma \\
8 & Male & CCO & CA & 20 years & Biotech SME \\
9 & Male & Head of Biologics & AU & 30 years & Big Pharma \\
10 & Female & CCO & US & 20 years & Biotech SME \\
11 & Male & CEO & AU & 35 years & Biotech SME \\
12 & Male & VP Corporate Strategy & AU & 25 years & Service Company \\
13 & Male & CCO & US & 20 years & Biotech SME \\
14 & Male & CEO & AU & 25 years & Biotech SME \\
\hline & & CA: Cana & CCO: & Commercal & Afficer
\end{tabular}

AU: Australia, BD: Business Development, CA: Canada, CCO: Chief Commercial Officer, CEO: Chief Executive Officer, CSO: Chief Scientific Officer, Dir.: Director, Ex.: Executive, SG: Singapore, Sr.: Senior, SME: Small and Medium-sized Enterprises, US: United States, VP: Vice President. 


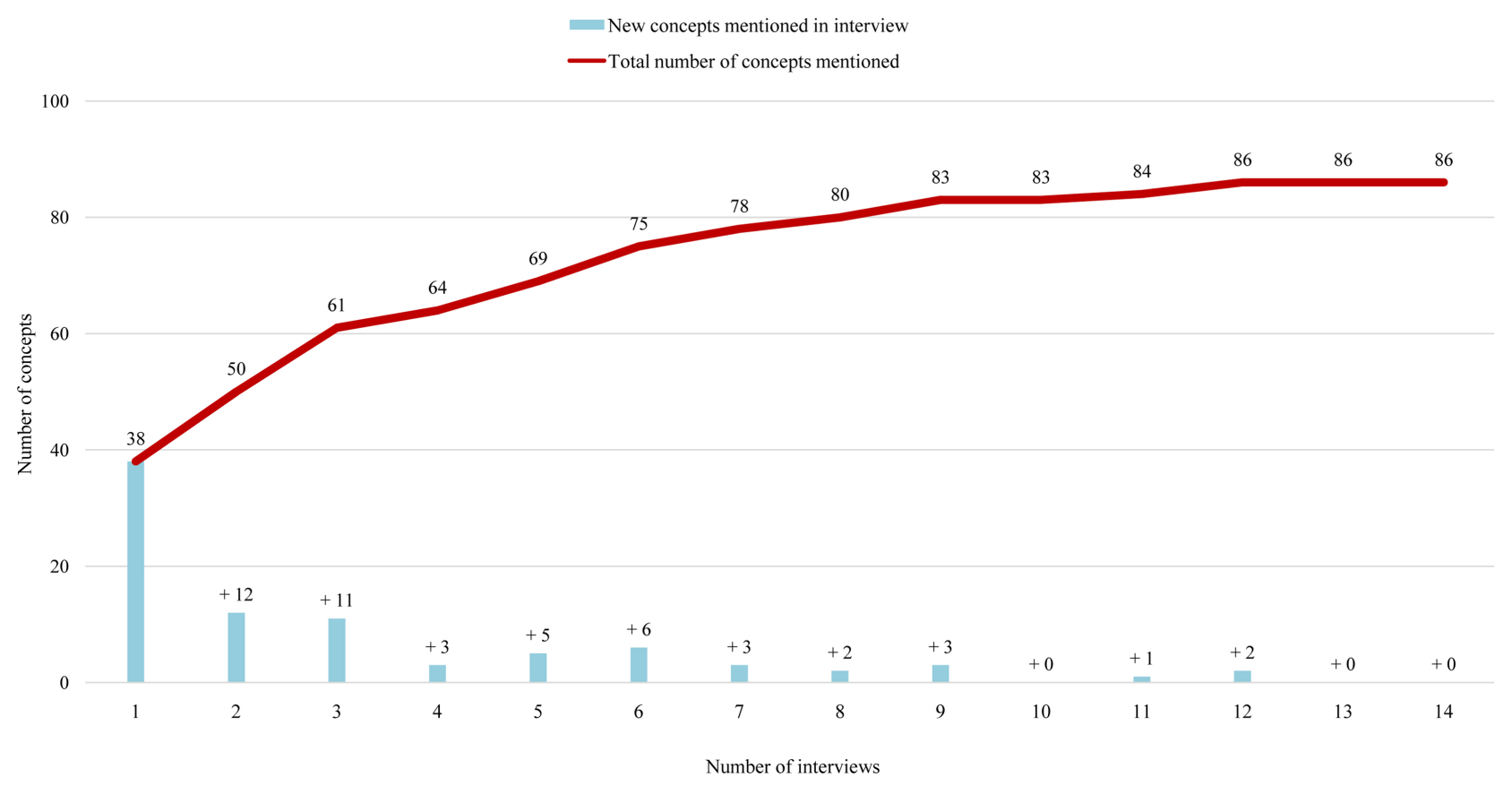

Figure 1. Data saturation curve for our sample.

mapped against the main stages of the SIVC, see Figure 2. Furthermore, we identified a similar analytical pattern that respondents consider for stakeholder stratification (reasoning and value), see Figure 3.

\subsubsection{Core Market Intelligence Map}

Figure 2 indicates the MI considerations we found and their position on the SIVC, indexed by keywords. Table 2 provides explanations and shows central stakeholders. The principle stakeholders here are: patients, providers, national regulatory agencies (NRAs), payers, and competitors. See Appendix 13 for working definitions.

Across SIVC stages Unmet needs assessment (U) and Demand articulation (A), overall unmet needs, governmental priorities and major interest groups (and the direction of their advocacy) are determined to assess the degree of demand/pull for specific interventions at the health system level. Primarily qualitative enquiry, such as review of public tenders, information on health ministry/NRA websites and scientific and grey literature, and personal conversations/interviews can provide pertinent information. At the Opportunity shaping and realization $(\mathrm{O})$ stage, target markets are characterized in-depth to evaluate the concrete business opportunity and market deployment feasibility. At this stage, analysis of secondary health-market data, provided by pertinent data analytics providers, or head-offices and subsidiaries, is the primary mode of inquiry. However, mixed-methods studies (in particular interviews and surveys) are useful for stakeholder stratification, as is the review of websites and literature for competition assessment, respectively. Across the Technical/Commercial development $(\mathrm{Dt} / \mathrm{Dc})$ and Production and upscaling $(\mathrm{P})$ stages, market deployment 


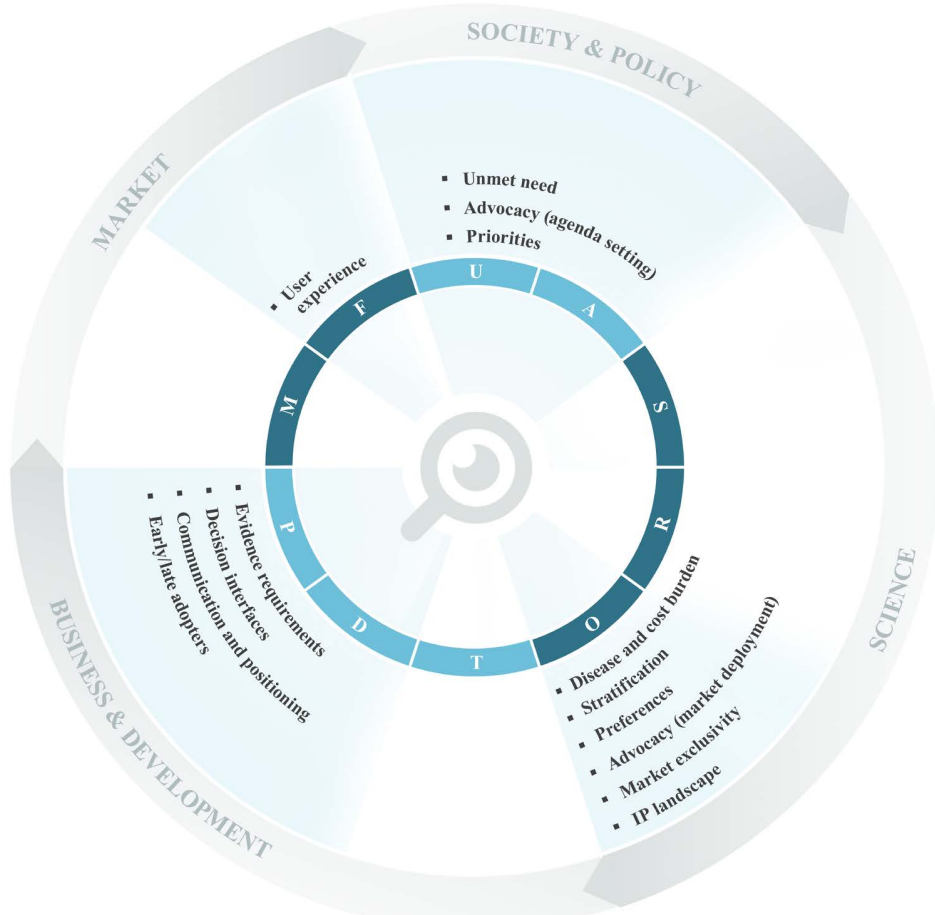

Figure 2. Market intelligence considerations mapped to the societal impact value cycle.

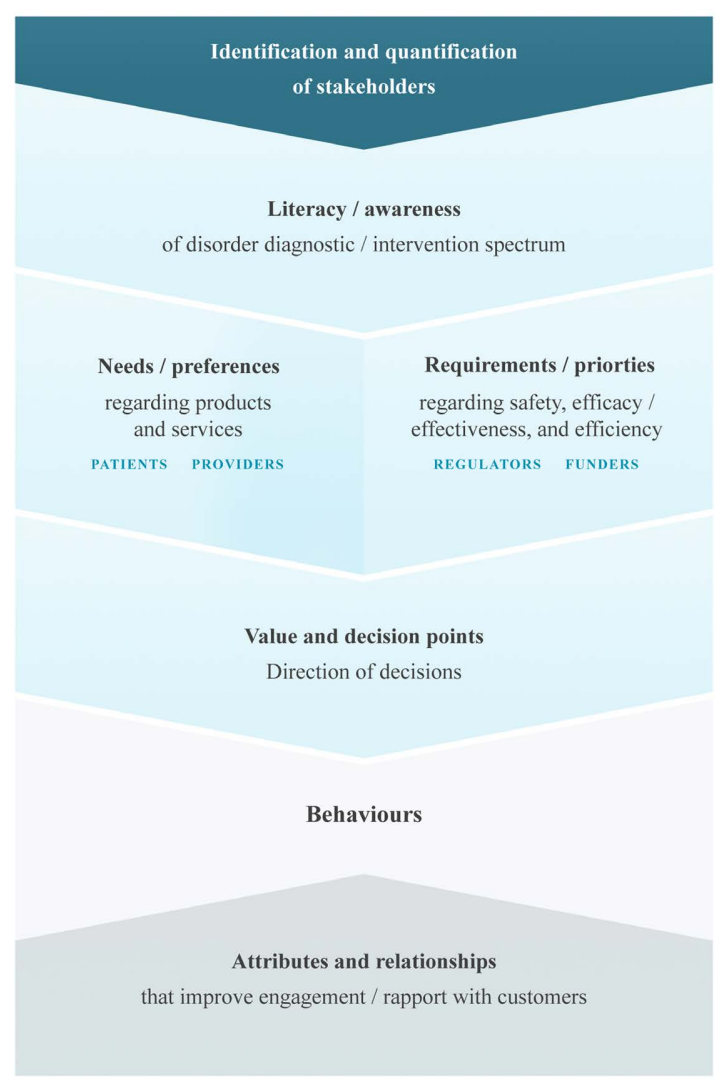

Figure 3. Stakeholder information flow and decision pathway model. 
Table 2. Market knowledge and stakeholder considerations. Considerations are sorted according to their stages on the societal impact value cycle, see Figure 2.

\begin{tabular}{|c|c|c|c|}
\hline $\begin{array}{l}\text { SIVC } \\
\text { stage }\end{array}$ & Theme & Considerations & $\begin{array}{l}\text { Stakeholders } \\
\text { involved }\end{array}$ \\
\hline \multirow{3}{*}{ U/A } & Unmet need & $\begin{array}{l}\text { Elicit awareness and literacy of stakeholders with disease/treatment } \\
\text { spectrum, and coping mechanisms to identify (in particular with leaders in } \\
\text { the field and societies) gaps in pre-existing knowledge and current disease } \\
\text { management_can include both clinical and non-clinical aspects. }\end{array}$ & $\begin{array}{c}\text { Patients; } \\
\text { Providers; } \\
\text { NRAs; Payers }\end{array}$ \\
\hline & $\begin{array}{c}\text { Advocacy } \\
\text { (agenda setting) }\end{array}$ & $\begin{array}{l}\text { Determine which individuals and groups (e.g. medical review boards, } \\
\text { policymakers, associations, societies) will support/oppose a new } \\
\text { intervention, which value they seek, and the impact they will likely have on } \\
\text { initial agenda-/priority-setting of other stakeholders/decision-makers-to } \\
\text { gauge intervention potential and improve stakeholder utility. }\end{array}$ & $\begin{array}{l}\text { Patient groups; } \\
\text { Providers } \\
\text { (+thought } \\
\text { leaders } \\
\text { and societies) }\end{array}$ \\
\hline & Priorities & $\begin{array}{l}\text { Determine priorities to, if possible, focus development on interventions } \\
\text { that will more likely receive (expedited) marketing authorisation and } \\
\text { market access: e.g. rare, severe, costly disease; no current or costly } \\
\text { treatment. }\end{array}$ & NRAs; Payers \\
\hline \multirow{6}{*}{$\mathrm{O}$} & $\begin{array}{l}\text { Disease and } \\
\text { cost burden }\end{array}$ & $\begin{array}{l}\text { Assess the overall/incremental burden and cost of the target disease for } \\
\text { health systems-cost of treatment/no treatment-to gauge the potential } \\
\text { of the market for proposed intervention. Cost feeds into evidence } \\
\text { requirements (market access). }\end{array}$ & \\
\hline & Stratification & $\begin{array}{l}\text { Identify, quantify and stratify stakeholders to determine intervention } \\
\text { market potential, key value targets and sources/recipients of market } \\
\text { intelligence. Criteria include: } \\
\text { - Patients: diagnosis, geographic location, and demographic and } \\
\text { socioeconomic status (e.g. price sensitivity) } \\
\text { - Providers: leader in the field, decision-maker at decision interfaces, } \\
\text { volume of patients/sales and experience, distribution across the market } \\
\text { - NRAs: institution(s) involved in regulation, their remits and } \\
\text { - } \quad \text { jurisdictions } \\
\text { - Compers: type (public/private) and size, location, risk-pools } \\
\text { Comproducts, therapeutic area, market share }\end{array}$ & $\begin{array}{l}\text { Patients; } \\
\text { Providers; } \\
\text { NRAs; Payers; } \\
\text { Competitors }\end{array}$ \\
\hline & Preferences & $\begin{array}{l}\text { Identify stakeholder intervention preferences, align TPPs with stakeholder } \\
\text { value accordingly, and co-develop and trial new interventions } \\
\text { (primarily with leaders in the field) to further improve value and utility } \\
\text { for stakeholders. }\end{array}$ & $\begin{array}{l}\text { Patients; } \\
\text { Providers; } \\
\text { NRAs }\end{array}$ \\
\hline & $\begin{array}{c}\text { Advocacy } \\
\text { (market } \\
\text { introduction) }\end{array}$ & $\begin{array}{l}\text { Determining which individuals and groups (e.g. payers, providers and } \\
\text { patients) will support or oppose a new intervention, and the impact they } \\
\text { will likely have on market introduction and on uptake-to address } \\
\text { barriers and improve market introduction prospects. }\end{array}$ & $\begin{array}{l}\text { Patient groups; } \\
\text { Providers } \\
\text { (in particular } \\
\text { thought leaders } \\
\text { and societies) }\end{array}$ \\
\hline & Market exclusivity & $\begin{array}{l}\text { Establish if development is first to market and which developments are or } \\
\text { might be in competitor pipelines (now, in future). If not first to market, } \\
\text { determine competitor sales volumes per product (or combinations thereof), } \\
\text { and the implications for own development activities. }\end{array}$ & Competitors \\
\hline & IP landscape & $\begin{array}{l}\text { Determine potential competitors' degree of IP protection and if market } \\
\text { has and enforces protection policies to evaluate the overall feasibility of } \\
\text { protecting IP and financial rewards, and if so, which strategy is most } \\
\text { promising/adequate. }\end{array}$ & Competitors \\
\hline
\end{tabular}




\begin{tabular}{|c|c|c|c|}
\hline \multirow{4}{*}{$\mathrm{D} / \mathrm{P}$} & $\begin{array}{l}\text { Evidence } \\
\text { requirements }\end{array}$ & $\begin{array}{l}\text { Identify which safety and efficacy data are required for marketing } \\
\text { authorisation (market introduction approval and post marketing data } \\
\text { monitoring commitments), and which cost-effectiveness data and types } \\
\text { of analyses are required for market access (formulary listing and } \\
\text { reimbursement approval) - to reduce delays and prevent rejection of } \\
\text { pertinent applications. In addition, conceive various approval scenarios } \\
\text { and their impact on uptake to assess which quantity of data (and level of } \\
\text { resources) is needed per scenario/for more favourable decisions. }\end{array}$ & $\begin{array}{l}\text { NRAs } \\
\text { (marketing } \\
\text { authorisation); } \\
\text { Payers } \\
\text { (market access) }\end{array}$ \\
\hline & Decision interfaces & $\begin{array}{l}\text { Map journey of patients through health system to determine their decision } \\
\text { points (and share of decision-making with providers) and thereby the } \\
\text { appropriate placement and maximum stakeholder value of interventions. }\end{array}$ & $\begin{array}{l}\text { Patients; } \\
\text { Providers }\end{array}$ \\
\hline & $\begin{array}{l}\text { Communication } \\
\text { and positioning }\end{array}$ & $\begin{array}{l}\text { Identify concerns and information (evidence) needs, as well as the types } \\
\text { of language and communication-style/presentation that resonate with } \\
\text { stakeholders to align engagement (communication and positioning) } \\
\text { strategies with stakeholder value. Concomitantly, assess competitor } \\
\text { positionings. }\end{array}$ & $\begin{array}{l}\text { Patients; } \\
\text { Providers; } \\
\text { Competitors }\end{array}$ \\
\hline & Early/late adopters & $\begin{array}{l}\text { Identify early and late adopters to determine who will (a) rapidly adopt } \\
\text { and utilise intervention and (b) stabilise utilisation over time-both } \\
\text { can have different information needs. }\end{array}$ & Providers \\
\hline $\mathrm{F}$ & $\begin{array}{c}\text { User } \\
\text { experience }\end{array}$ & $\begin{array}{l}\text { Elicit (dis-)advantages of (new) intervention and potentially existing } \\
\text { alternatives to fine-tune product (development), positioning, } \\
\text { engagement strategies and maximise user value. }\end{array}$ & $\begin{array}{l}\text { Patients; } \\
\text { Providers }\end{array}$ \\
\hline
\end{tabular}

facilitators are identified to prepare the market, and identify the evidence requirements for product introduction.

Interviews, in particular with providers and patient groups, can provide relevant data. Mapping of the patient journey via referrals and the information shared between providers helps identify crucial stakeholder value, interactions and decision-points. Importantly, for regulator and payer consideration, it is crucial to maximize a product's stakeholder utility by aligning target product profiles (TPPs) with provider preferences. Review of guidelines on NRA and payer websites, and of potentially existing previous applications and literature, helps innovators understand the type and quantity of data required for applications to regulators and payers. Finally, in stage Response and feedback (F), the experience of users with (recently introduced) interventions, and alternatives thereof, is elicited to understand and increase user-value, i.e. (health) outcomes, but also financial rewards for innovators. User experience is primarily collected in mixed-methods studies.

\subsubsection{Stakeholder Stratification and Value Determination Model}

Our analysis indicates, that, to better understand stakeholder reasoning and value, respondents consider similar information in sequential analysis across all principle stakeholders (Figure 3): first, they determine the baseline of stakeholder awareness, literacy and experience regarding the target condition and its management. This establishes an overview of which stakeholder is an appropri- 
ate source of which type and detail of information. Second, they focus sub-sequent analysis on stakeholder value, i.e. to understand pain points and preferences (patients and providers) or requirements and priorities (NRAs and payers). Both aforementioned steps support comprehension of the reasons for stakeholders' current decisions and indicate how products/services and positioning strategies can be designed or modified to align with stakeholder benefits.

Finally, our respondents elicit which stakeholder requires which type and detail of information, and which "language", or style, of presentation resonates with them. This informs the design and improvement of engagement strategies to, in turn, improve disease awareness/literacy and how a new intervention addresses the former. Importantly, thoughtfully designed engagement strategies facilitate trust and maintain rapport. However, they can also adversely impact on decisions and, in consequence, behaviours. Pertinent intelligence is primarily sourced through interviews and surveys.

\subsubsection{Market Research Checklists}

As alluded to above, we first stratified our data by stakeholder. These data have been tabulated into detailed checklists that are sub-categorized into Stakeholder and target mapping, Stakeholder decision drivers, and Stakeholder engagement, see Appendixes 5-9. For a list of responses to MI, see Appendix 11.

\section{Discussion}

We provide here the first market orientation-based overview of market intelligence considerations pertinent to the biopharmaceutics sector, methods of their elicitation and examples of health intervention improvement. Our results map readily to six out of ten stages of the Societal Impact Value Cycle, providing innovators with an accessible overview and orientation. For stakeholder stratification and analysis, we present a synthesised model that supports innovators in tracing and understanding stakeholder reasoning, decision-points and value. Our findings are also related to the findings of a recent study that identified key factors of successful innovation for the probiotic sector. In combination, our illustrations, checklists and elaborations can be used as an integrated toolbox for innovators to perform their own basic market research, analysis and response activities.

\subsection{Closing the Research Gap}

Various studies have found a positive correlation between a company's degree of $\mathrm{MO}$ and its product and organisational performance, for both first-to-market and late-entrants [22]. Evidence suggests that the sooner innovators increase their degree of MO, the more sustainable their stakeholder and market alignment (and competitive advantage) is [34]. Our findings even suggest that the Pareto principle applies to market research: rapid (and early) review of easily accessible resources can provide substantial and relevant decision information. As market analysis plays such an important role for improving the potential so- 
cietal value of new health interventions, it is all the more surprising that there exists paucity of market research direction for innovators in the biopharmaceutics sector. Our study addresses this important gap in the current body of MO literature and provides actionable guidance to reduce information discrepancy between innovators and their target market needs.

\subsection{Improving MO across Stakeholders}

Being able to readily map our results against six out of ten stages of the SIVC has facilitated their meaningful stratification across a novel and pertinent innovation framework. It also emphasises, once again, the high degree of market information fragmentation across diverse stakeholders involved in the innovation process, as also observed by others [15]. A recent study found that even basic definitions of unmet needs are not identical across stakeholders [35]. This is problematic as concerted efforts based on shared understanding, awareness of and alignment towards needs and preferences of relevant actors, are required to maximise the value of interventions for society. On a more encouraging note, one of our respondents mentioned that one regulator liaises with providers and patients to identify unmet needs, and with companies to assess regulatory time-lines and the compassionate use of medicines in clinical trials. We contend that policies to incentivise the system-wide overall increase of MO should be more thoroughly explored for all relevant stakeholders, irrespective of if they add value to new interventions by, for example, vetting the safety and quality, or covering the costs, thereof. Systematic support (and empowerment) of all stakeholders to this end could lead to various benefits. For example, the long-term reduction of information fragmentation could contribute to strengthening and streamlining collaboration in healthcare innovation processes. However, to be effective, support must be nuanced and acknowledge the specific role and contribution of individual stakeholders, and stakeholder:stakeholder interfaces to de facto increase overall MO.

\subsection{Informing Health Decision Models}

In addition to providing an analytical sequence of data per stakeholder, our stratification model is well-suited to inform and complement the population of decision support systems in the healthcare sector. Multi-criteria decision analysis (MCDA), which takes into account diverse, and potentially conflicting, criteria and requirements, is being used for reimbursement prioritisation in market access decisions [36] [37]. Recently, MCDA has been investigated as a decision tool for regulators assessing applications [38], but also suggested as a payer decision prediction tool for R\&D organisations [39]. If innovators had, across various markets, access to stakeholder MCDA requirement profiles, which could be elicited and structured based on our stakeholder stratification model, the burden of MI collection and barriers for intervention improvement could be, potentially significantly, decreased. In addition, such profiles could improve the level of de- 
tail of needs for better segmentation of markets, group markets with similar stakeholder and need profiles, etc., and reduce resource consumption for MI.

\subsection{Consideration across Health Sectors}

Our findings also relate to a range of key factors of successful innovation as identified in a recent study for probiotics [15], further indicating the relevance of MI and orientation across industries in the broader healthcare sector with differential pain points and requirements. First, regarding early phases of technical development, our interviewees stated the importance of incorporating considerations relating to stakeholder value and decision-points at an early stage. In addition, our respondents highlighted that, to improve resource allocation and collecting evidence for applications with regulators and payers, it is important to align as closely as possible TPPs (target product profiles) with provider and patient preferences. The key factors of successful innovation, however, do not include payers, which is not surprising as probiotics usually do not require an intermediary institutional payer. Second, when designing early market introduction strategies, our interviewees (primarily referring to prescription interventions) indicated that interactions with leaders in the field can facilitate collaborations and help establish or increase awareness of the medical need and potential intervention(s) among healthcare providers. In addition to said interactions, the key factors of successful innovation include issues related to determining sales channels and strong competition on retailer shelves (for functional foods). Although of secondary nature, this was also a theme in our data pertinent to OTC products sold by pharmacies. Nevertheless, innovators in the biopharmaceutics industry should have a clear understanding of how their product will be classified and accessed, and who will be the payer. A timely example of novel classifications, in this case for the hospital-market, is CAR-T therapy in Australia: on one hand, it is regulated as a biologic and not a prescription medicine and, on the other, reimbursed as a medical service rather than a pharmaceutical [40] [41]. Third, while the key factors of successful innovation highlight the importance of good manufacturing practices (GMP), GMP was not a central theme in our data. This is surprising, as in particular in the biopharmaceutics industry, GMP and the specific quality standards that underpin GMP are mandated and monitored by regulators in essentially all markets, and indeed GMP standards can be identified by market research. [42] However, this might be due to the fact that the implementation of GMP is not primarily a marketing-related activity. Nevertheless, this once again shows that market research informs and aligns various stages of development or, in this case, manufacturing and evidence needs respectively with market requirements. Finally, our interviewees stated the importance of eliciting and responding to market feedback by improving their interventions and engagement strategies to better match customer needs. Regarding responses to market feedback, the key factors of successful innovation focus on inference of future customer needs from market feedback. Our respondents, on the other hand, emphasised the extrapolation of future needs by mon- 
itoring competitor pipelines and potential changes in regulator and payer priorities. Forecasting is an important function of $\mathrm{MO}$ and our stakeholder information and decision pathway model is suited to guide innovators in their assessment of the (future) needs and activities of diverse stakeholders, and indeed of the other above-mentioned factors.

\subsection{Strengths and Limitations}

By focussing exclusively on senior executives and marketing experts of the biopharmaceutics sector, our study provides evidence particularly pertinent to academic entrepreneurs developing new medical interventions. Our sample ranged from both consolidated as well as highly dynamic markets increasing the degree of external validity. In line with other works [29], we reached data saturation at the end of the 12th interview. This confirms that we asked a specific research question to a specific group of stakeholders. Additionally, the use of a consolidated theoretical framework and two researchers working in tandem improved the validity of data collection and analysis. This study provides a clear overview of the factors that are important primarily for prescription drugs because it was the type of intervention respondents alluded to most frequently. It is conceivable that for OTC drugs different aspects play a role, especially with regard to payers. Future studies could therefore explore differences between prescription and OTC interventions. Moreover, to fully understand the extent to which different factors resonate in society, a quantitative follow-up study could investigate, if priorities exist in our results across various stakeholders.

\subsection{Implications for Policy}

Above, we have primarily appealed to innovators to perform market research. Funding models can readily support innovators with market research, especially those developing interventions that promise step improvements in disease management. Importantly, a decreased dependence on private funding, for which incentives can be misaligned with unmet need, [43] with access to a market research toolbox, such as the one proposed here, could persuade innovators to invest more resources in market research. Issuers of public tenders, and in particular seed funds that can have a major impact on the sustainability of growth of (biotech) start-ups [44], are in a unique position to incentivize market research activities as early as possible [45]. In addition, some funding consortia, e.g. European Innovation Council [46], also offer coaching services that can include access to MI via partner networks [47]. They can thereby support innovators in, first, appreciating that market research is not merely an academic exercise but rather, serves to fundamentally inform them of the value judgements of their target audiences, and options to improve their interventions and the societal impact they are, in all likelihood, seeking; and, second, understanding which potential barriers they might face if they do not align their developments with the needs of stakeholders. Naturally, with available product-specific market research data, funders would have better grounds to evaluate the probability of 
new developments meeting the requirements of stakeholders and take decisions on further funding, and, over time, establish a baseline of experience with MI data facilitating differential decision outcomes. Funding models could also include earmarked budgets: first, limited funding for innovators to conduct basic market research (pre-application) - to inform the funding decision; and second, should development funding be approved, more substantial financial support for thorough market research-to align interventions with the needs of market(s).

\subsection{Prioritising MI Considerations}

Because our study is exploratory, it can be considered a starting point for future, more targeted research into the impact of different MI aspects on development timelines, health technology assessment, commercialisation success, etc., of therapeutic interventions. For example, although analysts might agree that certain MI considerations are important, it might not be clear which specific considerations and to which degree contribute to the success of interventions. Moreover, as alluded to above, besides MI a host of determinants exist that can drive the success of new interventions, and their utility for society. Similarly, future research could assess and quantify the relative contribution, and hence value, of each of these innovation drivers. Thereby, an overview of innovation policy blind-spots and corresponding priorities could be created to inform innovator support strategies.

\section{Conclusion}

The scholarly enquiry into marketing in the biopharmaceutics sector is in the early stages. This is surprising when considering the utility that proper market research can provide to increase the long-term societal return-on-investment of new health interventions. This study provides the first overview of market orientation-based market intelligence considerations for the biopharmaceutics sector. Our toolbox for guiding data collection and analysis, and translation of insights into actions can be of interest to both innovators and policymakers: by pinpointing relevant considerations, steps and activities to specific innovation stages, our findings can improve understanding of stakeholder needs and changes thereof over time, inform new interventions and maximise value for society. The importance of integrating insights from market intelligence with product development at the earliest stage possible cannot be overstated.

\section{Conflicts of Interest}

The authors declare no conflicts of interest regarding the publication of this paper.

\section{References}

[1] Tran, J., Norton, R., Conrad, N., Rahimian, F., Canoy, D., Nazarzadeh, M. and Rahimi, K. (2018) Patterns and Temporal Trends of Comorbidity among Adult Patients with Incident Cardiovascular Disease in the UK between 2000 and 2014: A 
Population-Based Cohort Study. PLoS Medicine, 15, Article ID: e1002513. https://doi.org/10.1371/journal.pmed.1002513

[2] Ording, A.G. and Sorensen, H.T. (2013) Concepts of Comorbidities, Multiple Morbidities, Complications, and Their Clinical Epidemiologic Analogs. Clinical Epidemiology, 5, 199-203. https://doi.org/10.2147/CLEP.S45305

[3] Angelis, A., Tordrup, D. and Kanavos, P. (2017) Is the Funding of Public National Health Systems Sustainable over the Long Term? Evidence from Eight OECD Countries. Global Policy, 8, 7-22. https://doi.org/10.1111/1758-5899.12341

[4] Institute for Public Policy Research (IPPR) (2018) The Lord Darzi Review of Health and Care: Interim Report. Institute for Public Policy Research, London.

[5] Belloni, A., Morgan, D. and Paris, V. (2016) Pharmaceutical Expenditure and Policies. Organization for Economic Co-Operation and Development, Paris.

[6] OECD (2017) Health at a Glance 2017. Organization for Economic Co-Operation and Development, Paris.

[7] Fernald, K., Pennings, E. and Claassen, E. (2015) Biotechnology Commercialization Strategies: Risk and Return in Interfirm Cooperation. Journal of Product Innovation Management, 32, 971-996. https://doi.org/10.1111/jpim.12218

[8] Kola, I. and Landis, J. (2004) Can the Pharmaceutical Industry Reduce Attrition Rates? Nature Reviews Drug Discovery, 3, 711-716. https://doi.org/10.1038/nrd1470

[9] Resnick, S.M., Cheng, R., Simpson, M. and Lourenço, F. (2016) Marketing in SMEs: a “4Ps" Self-Branding Model. International Journal of Entrepreneurial Behavior \& Research, 22, 155-174. https://doi.org/10.1108/IJEBR-07-2014-0139

[10] Choi, G.-E., Bolan, P., Hutchinson, K. and Mitchell, R. (2014) Social Media Implementation by SMEs: Overcoming the Challenges of Measurement. British Academy of Management (BAM), London.

[11] Fillis, I. (2002) Small Firm Marketing Theory and Practice: Insights from the Outside. Journal of Research in Marketing and Entrepreneurship, 4, 134-157. https://doi.org/10.1108/14715200280001469

[12] Gilmore, A. (2007) Emarketing and SMEs: Operational Lessons for the Future. European Business Review, 19, 234-247. https://doi.org/10.1108/09555340710746482

[13] Lehoux, P., Daudelin, G., Hivon, M., Miller, F.A. and Denis, J.-L. (2014) How Do Values Shape Technology Design? An Exploration of What Makes the Pursuit of Health and Wealth Legitimate in Academic Spin-Offs. Sociology of Health \& Illness, 36, 738-755. https://doi.org/10.1111/1467-9566.12097

[14] Lehoux, P., Miller, F.A., Daudelin, G. and Denis, J.L. (2017) Providing Value to New Health Technology: The Early Contribution of Entrepreneurs, Investors, and Regulatory Agencies. International Journal of Health Policy and Management, 6, 509-518. https://doi.org/10.15171/ijhpm.2017.11

[15] Van de Burgwal, L.H.M., Van der Waal, M.B. and Claassen, E. (2018) Accelerating Microbiota Product Development: The Societal Impact Value Cycle as a Conceptual Model to Shape and Improve Public-Private Valorization Processes. PharmaNutrition, 6, 157-168. https://doi.org/10.1016/j.phanu.2018.07.002

[16] Bloom, D.E. (2015) Valuing Vaccines: Deficiencies and Remedies. Vaccine, 33, B29-B33. https://doi.org/10.1016/j.vaccine.2015.03.023

[17] Drummond, M.F., Sculpher, M.J., Claxton, K., Stoddart, G.L. and Torrance, G.W. (2015) Methods for the Economic Evaluation of Health Care Programmes. Oxford University Press, Oxford.

[18] van de Burgwal, L.H.M., Dias, A. and Claassen, E. (2019) Incentives for Knowledge 
Valorisation: A European Benchmark. The Journal of Technology Transfer, 44, 1-20. https://doi.org/10.1007/s10961-017-9594-8

[19] Kohli, A.K. and Jaworski, B.J. (1990) Market Orientation: The Construct, Research Propositions, and Managerial Implications. Journal of Marketing, 54, 1-18. https://doi.org/10.1177/002224299005400201

[20] Najafi-Tavani, S., Sharifi, H. and Najafi-Tavani, Z. (2016) Market Orientation, Marketing Capability, and New Product Performance: The Moderating Role of Absorptive Capacity. Journal of Business Research, 69, 5059-5064. https://doi.org/10.1177/002224299005400201

[21] Kam Sing Wong, S. (2012) The Influence of Market Orientation on New Product Success. European Journal of Innovation Management, 15, 99-121. https://doi.org/10.1108/14601061211192852

[22] Rodríguez-Pinto, J., Carbonell, P. and Rodríguez-Escudero, A.I. (2011) Speed or quality? How the Order of Market Entry Influences the Relationship between Market Orientation and New Product Performance. International Journal of Research in Marketing, 28, 145-154. https://doi.org/10.1016/j.ijresmar.2011.02.001

[23] Carbonell, P. (2010) The Effect of Market Orientation on Innovation Speed and New Product Performance. Journal of Business and Industrial Marketing, 25, 501-513. https://doi.org/10.1108/08858621011077736

[24] Mahmoud, M.A., Kastner, A. and Yeboah, J. (2010) Antecedents, Environmental Moderators and Consequences of Market Orientation: A Study of Pharmaceutical Firms in Ghana. Journal of Medical Marketing, 10, 231-244.

https://doi.org/10.1057/jmm.2010.12

[25] Appiah-adu, K. and Ranchhod, A. (1998) Market Orientation and Performance in the Biotechnology Industry: An Exploratory Empirical Analysis. Technology Analysis \& Strategic Management, 10, 197-210. https://doi.org/10.1080/09537329808524311

[26] Reid, M. and Brady, E. (2012) Improving Firm Performance through NPD: The Role of Market Orientation, NPD Orientation and the NPD Process. Australasian Marketing Journal (AM), 20, 235-241. https://doi.org/10.1016/j.ausmj.2012.05.011

[27] Brink, P.J. (1991) Qualitative Nursing Research: A Contemporary Dialogue. SAGE Publications, Inc., Thousand Oaks.

[28] Glaser, B.G. and Strauss, A.L. (2017) Discovery of Grounded Theory: Strategies for Qualitative Research. Routledge, New York. https://doi.org/10.4324/9780203793206

[29] Guest, G., Bunce, A. and Johnson, L. (2006) How Many Interviews Are Enough? An Experiment with Data Saturation and Variability. Field Methods, 18, 59-82. https://doi.org/10.1177/1525822X05279903

[30] Koelsch, L.E. (2013) Reconceptualizing the Member Check Interview. International Journal of Qualitative Methods, 12, 168-179. https://doi.org/10.1177/160940691301200105

[31] Boyatzis, R.E. (1998) Transforming Qualitative Information: Thematic Analysis and Code Development. Sage Publications, Inc., Thousand Oaks.

[32] Braun, V. and Clarke, V. (2006) Using Thematic Analysis in Psychology. Qualitative Research in Psychology, 3, 77-101. https://doi.org/10.1191/1478088706qp063oa

[33] Daly, J., Kellehear, A. and Gliksman, M. (1997) The Public Health Researcher: A Methodological Guide. Oxford University Press, Oxford.

[34] Kumar, V., Jones, E., Venkatesan, R. and Leone, R.P. (2011) Is Market Orientation a Source of Sustainable Competitive Advantage or Simply the Cost of Competing? 
Journal of Marketing, 75, 16-30.

[35] Vreman, R.A., Heikkinen, I., Schuurman, A., Sapede, C., Garcia, J.L., Hedberg, N., Athanasiou, D., Grueger, J., Leufkens, H.G.M. and Goettsch, W.G. (2019) Unmet Medical Need: An Introduction to Definitions and Stakeholder Perceptions. Value in Health, 22, 1275-1282. https://doi.org/10.1016/j.jval.2019.07.007

[36] Baltussen, R., Marsh, K., Thokala, P., Diaby, V., Castro, H., Cleemput, I., Garau, M., Iskrov, G., Olyaeemanesh, A., Mirelman, A., Mobinizadeh, M., Morton, A., Tringali, M., van Til, J., Valentim, J., Wagner, M., Youngkong, S., Zah, V., Toll, A., Jansen, M., Bijlmakers, L., Oortwijn, W. and Broekhuizen, H. (2019) Multicriteria Decision Analysis to Support Health Technology Assessment Agencies: Benefits, Limitations, and the Way Forward. Value in Health, 22, 1283-1288.

https://doi.org/10.1016/j.jval.2019.06.014

[37] Marsh, K., Thokala, P., Youngkong, S. and Chalkidou, K. (2018) Incorporating MCDA into HTA: Challenges and Potential Solutions, with a Focus on Lower Income Settings. Cost Effectiveness and Resource Allocation, 16, Article No. 43. https://doi.org/10.1186/s12962-018-0125-8

[38] Goetghebeur, M.M., Wagner, M., Nikodem, M., Zyla, A., Micaleff, A. and Amzal, B. (2016) Pragmatic Multicriteria Decision Analysis (MCDA) Combined with Advanced Pharmacoepidemiology for Benefit-Risk Assessments of Medicines Adapted to the Real-Life Constraints of Regulators: Development and Case Study. Therapeutic Innovation \& Regulatory Science, 50, 620-631.

https://doi.org/10.1177/2168479016642812

[39] Williams, P., Mauskopf, J., Lebiecki, J. and Kilburg, A. (2014) Using Multicriteria Decision Analysis during Drug Development to Predict Reimbursement Decisions. Journal of Market Access \& Health Policy, 2, Article ID: 25270. https://doi.org/10.3402/jmahp.v2.25270

[40] The Therapeutic Goods Administration (2020) Classification of Biologicals. Australian Government Department of Health, Canberra.

[41] Medical Services Advisory Committee (2019) 1519-Tisagenlecleucel (CTL019) for Treatment of Refractory CD19-Positive Leukaemia and Lymphoma.

[42] Bunn, G.P. (2019) Good Manufacturing Practices for Pharmaceuticals. 7th Edition, CRC Press, Boca Raton. https://doi.org/10.1201/9781315120669

[43] Panteli, D. and Edwards, S. (2018) Ensuring Access to Medicines: How to Stimulate Innovation to Meet Patients' Needs? World Health Organization, Geneva.

[44] Nishimura, J., Tsai, Y. and Nagaoka, S. (2019) Impact of Initial Seeds on the Growth of Biotechnology Startups: Evidence from the U.S. and Japan. Economics of Innovation and New Technology, 28, 695-721.

https://doi.org/10.1080/10438599.2018.1557410

[45] Ayoub, M.R., Gottschalk, S. and Müller, B. (2017) Impact of Public Seed-Funding on Academic Spin-Offs. The Journal of Technology Transfer, 42, 1100-1124. https://doi.org/10.1007/s10961-016-9476-5

[46] European Innovation Council (2020) Enhanced European Innovation Council (EIC) Pilot.

[47] Enterprise Europe Network (2020) Advice for International Growth. Enterprise Europe Network.

[48] Toumi, M. (2017) Introduction to Market Access for Pharmaceuticals. CRC Press, Boca Raton. https://doi.org/10.1201/9781315314600 


\section{Supplementary Materials}

\section{Appendix 1}

Simplified version of the societal impact value cycle

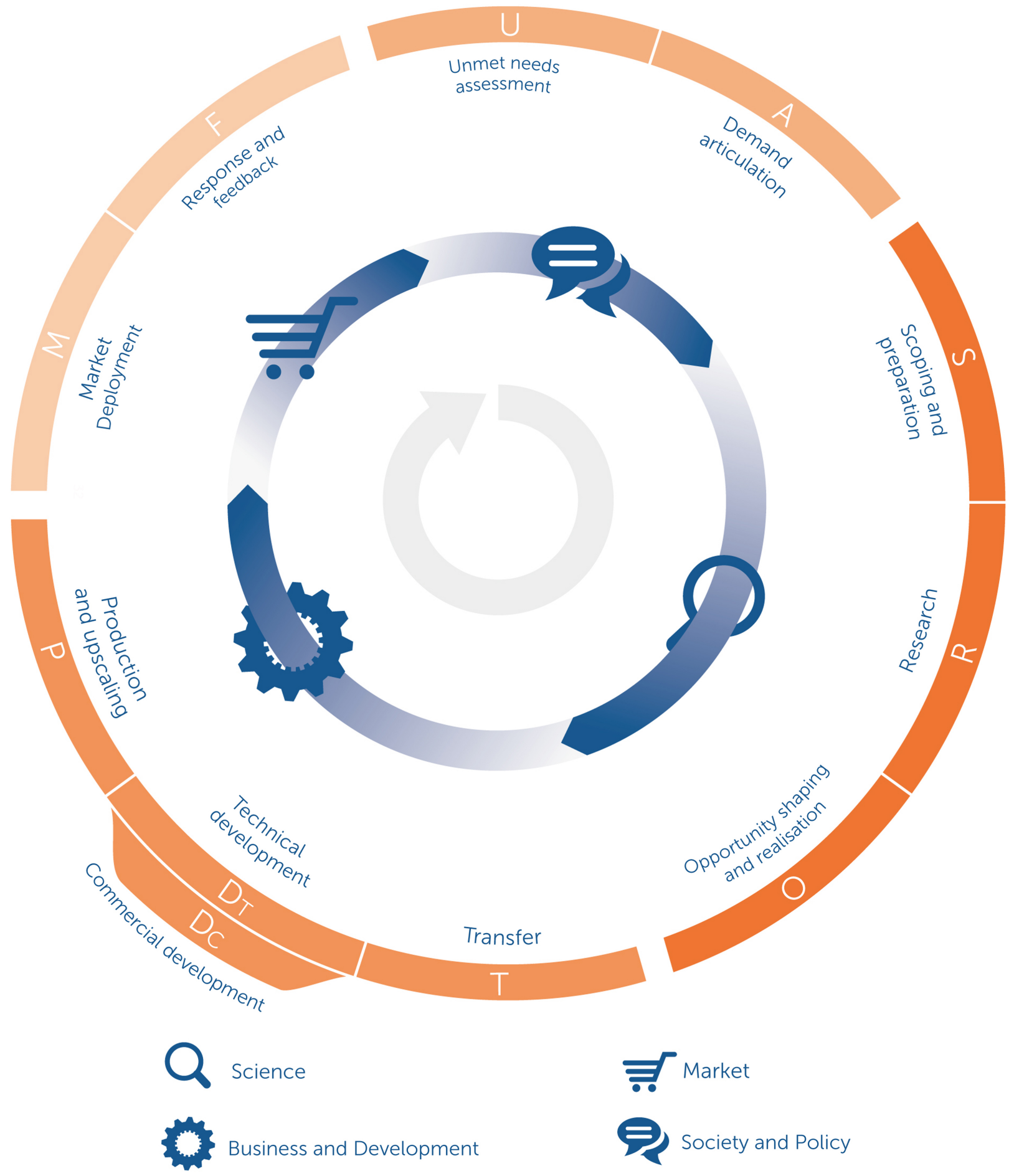

Appendix 2

Interview guide and flow diagram 


\section{Schematic/flow of interviews/questions}

Interviewee presented with research gap/justification for study and additional clarifying information (e.g. why their expertise is considered essential)

Opening: Demographics

For how long have you been working in the biopharmaceutical industry?

What are your current responsibilities?

-

\section{Theme: Generation \\ Q1: How do you define your market opportunity? \\ Q2: How do you define the target customer group for a} therapeutic product?

Q3: How do you anticipate your customers' needs?

Q4: What are the key factors considered in assessing the market access environment of a new therapeutic product?

Q5: What do you consider as important in monitoring the competitive landscape?

Q6: How would you tailor a therapeutic product to you customers' needs?

\section{Q7: Are there any other factors you consider in your market} research?

\section{Theme: Dissemination}

Q8: Is everyone in your organisation aware of the market knowledge acquired by your company?

Theme: Reponsiveness

Q9: How do you respond to the market knowledge generated by your company?

Closing: final question/recommendation

Q10: Is there anything else you would like to add based on the topics we have discussed?

Q11: Can you recommend anyone that might be interesting to

interview as well?

\section{.}

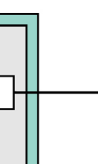

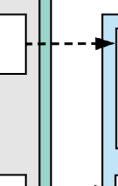

3 detail questions

Probing

- Q2.1: What would you consider as most important?

- Q2.2: The epidemiology of the disease?

- Q2.3: The (unmet) medical need?

4 detail questions

- Q3.1: What would you consider as most important?

- Q3.2: The patient pathway?

- Q3.3: The (customer) channels?

- Q3.4: Decision makers?

3 detail questions

- Q4.1: What is the relation of key factors to your customers' needs?

- Q4.2: The reimbursement environment?

- Q4.3: The regulatory landscape?

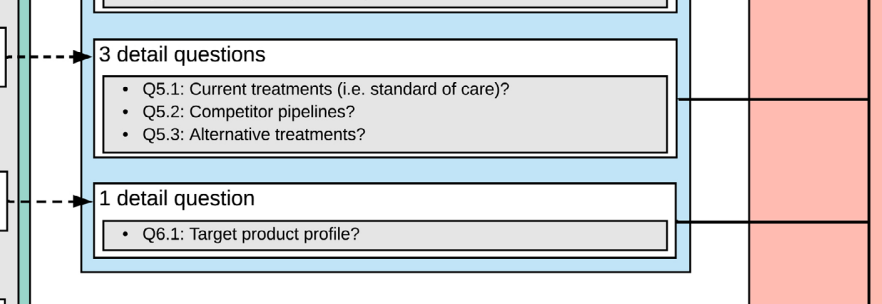

- Q5.1: Current treatments (i.e. standard of care)?

- Q5.3: Alternative treatments?

- Q6.1: Target product profile?

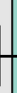

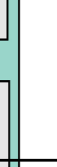

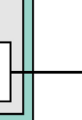

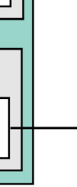




\section{Appendix 3}

Composition of our sample (invitees versus participants).

\begin{tabular}{ccc}
\hline Region & Invitees & Participants \\
\hline USA & 52 & 1 \\
Australia & 18 & 9 \\
Canada & 5 & 2 \\
Europe (Austria, France, Ireland, UK) & 4 & 1 \\
APAC (Singapore) & 1 & 1 \\
Total & 80 & 14 \\
Background & & \\
Big Pharma & 18 & 5 \\
Consultant & 1 & 1 \\
SME Biotech & 36 & 3 \\
SME Pharma & 25 & 5 \\
Total & 80 & 14 \\
\hline
\end{tabular}

\section{Appendix 4}

Unique concepts mentioned per interview-colour coding indicates the interview in which a concept was first mentioned, and the numbers indicate frequency per interview.

\section{Respondent (and frequency)}

\begin{tabular}{|c|c|c|c|c|c|c|c|c|c|c|c|c|c|c|}
\hline \multirow{2}{*}{ Unique concept } & \\
\hline & A & $\mathrm{B}$ & $\mathrm{C}$ & $\mathrm{D}$ & $\mathrm{E}$ & $\mathrm{F}$ & G & $\mathrm{H}$ & I & $\mathrm{J}$ & K & $\mathrm{L}$ & M & $\mathrm{N}$ \\
\hline Ad boards & & & & & & & & 1 & & & & & & \\
\hline Additional testing & 1 & & & 1 & 1 & & & 1 & & & & & & \\
\hline Additional therapies & & 2 & & & & & & & & & & & 1 & \\
\hline Adherence/Compliance & 2 & 1 & 1 & & & & & & & 1 & & & & \\
\hline Alter delivery system & 1 & & & & & & & & & & & & & \\
\hline Alter dosing regime & 1 & & & & & & & & & 1 & 1 & & & 1 \\
\hline Awareness Adoption Curve & & & 1 & & & & & & & & & & & \\
\hline Combination therapy? & & 1 & & & & & & & & & & & & \\
\hline Competitor pipelines & & & 2 & & 1 & 1 & 1 & & 2 & 1 & 2 & 1 & & 1 \\
\hline Competitor positioning & 1 & & & & 1 & 1 & 2 & 1 & 2 & 1 & 1 & 1 & 2 & \\
\hline Competitor priorities & & & & & & 1 & 1 & & & 1 & & & 1 & \\
\hline Competitor product perception & 1 & & & & & & & 1 & 2 & 1 & & & 3 & \\
\hline Competitor promotional activities & & & & & & 1 & 1 & & 1 & & & & 1 & \\
\hline Competitor pros and cons & 2 & & & & & 1 & & 1 & & 1 & & & 1 & \\
\hline
\end{tabular}


Competitor regulatory position

Competitor sales data

Competitor TPPs

Conjoint analysis

Cost-effectiveness analysis

Disease epidemiology

Emotional insights

Engage KOLs

EXAMPLE: Alter product

Expand Indication

Forecast

Health economics analysis

Identify alternative treatments

Identify channels

Identify clinical endpoints

Identify decision points (BPE)

Identify decision-makers

Identify demand*

Identify differentiation opportunity

Identify disease burden

Identify disease perception

Identify indication

Identify key target audience

Identify KOLs

Identify optimal TPP

Identify other types of MPs

Identify payer environment

Identify price points (PSA)

Identify product messaging

Identify provider drivers

Identify regulatory requirements

Identify side-effect profile

Identify unmet medical need

Identify value for payers

Identify your unique selling features

Informed patient
1

$\begin{array}{ll}1 & 1 \\ 1 & 2\end{array}$

2

$\begin{array}{lll}2 & 1 & 1\end{array}$

21

13

2

1

14

13

21

12

2

2

1

$1-1$

$\begin{array}{lllllllllll}1 & 1 & 1 & 1 & 1 & 1 & 1 & 1 & 1 & 3 & 1\end{array}$

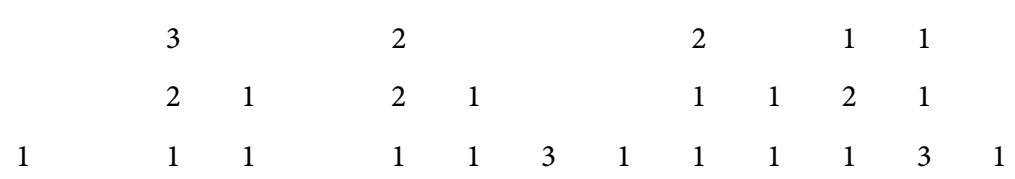

3

1

21

1

2

3

2

1

$\begin{array}{llll}1 & 1 & 1 & 1\end{array}$

1

$\begin{array}{llllllllllll}2 & 2 & 4 & 1 & 3 & 1 & 4 & 2 & 1 & 3 & 1 & 2 \\ 1 & & & 1 & 3 & & 3 & 1 & 1 & & & \\ 2 & & & & & & 3 & & & & & \end{array}$

1

$\begin{array}{llllll}2 & & 1 & 1 & 1 & 1 \\ 1 & 1 & 1 & 1 & 1 & 1\end{array}$

1

12

21

1

1

21

$\begin{array}{lllll}1 & 1 & 2 & 1 & 1\end{array}$

Launch data

2 


\section{Continued}

Long-term view

Map patients

Market profiling

Market share?

Medical plan

Model-based meta-analysis

More attractive partner

MR dissemination

Patient finance

PATIENT JOURNEY

Patient profiling

Patient societies

Prepare the market

Primary market research

Prior relationship with decision-makers

Product exclusivity

Product fit in

Product packaging

Product perception

Product prioritising

Product profile

Product uptake

Provide education

Provider Targeting

Publicly available data

Qualitative market research

Quantitative market research

Regulatory label

RESPONSIVENESS

Therapy switch (doctor)

Therapy switch (patient)

Therapy switch (payers)

Treatment regimen

Virtual development teams

1

12
2

$\begin{array}{lll}1 & 1 & 1 \\ 1 & 2 & \\ 1 & 3 & \end{array}$

$\begin{array}{lllll} & & 1 & 1 & \\ 1 & 1 & 1 & 2 & 1 \\ & & & 1 & \end{array}$

2

$2 \quad 1 \quad 1$

$\begin{array}{llllllllllllll}1 & 1 & 1 & 2 & 2 & 2 & 2 & 2 & 2 & 2 & 2 & 1 & 2 & 2\end{array}$

\begin{tabular}{|c|c|c|c|c|c|c|c|c|c|c|c|}
\hline & & & 1 & & & & & 1 & & & \\
\hline & & & & 1 & 1 & & & 1 & 1 & 2 & 1 \\
\hline 3 & 3 & & 1 & 4 & 1 & 1 & 1 & 1 & 1 & & 2 \\
\hline 1 & 2 & 1 & 1 & & & & 1 & & & & \\
\hline 1 & 1 & 1 & & 1 & & & & & & & 1 \\
\hline
\end{tabular}

1

1

$\begin{array}{lll}1 & 1 & 2\end{array}$

1

1

2

1

$\begin{array}{lll}2 & 2 & 1\end{array}$

1

1

1

1

22

Wholesaler data

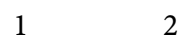

12

$1 \quad 1$

$2 \quad 1 \quad 2$

1

1

1

11

$\begin{array}{ll}3 & 1\end{array}$

$\begin{array}{lll}1 & 2 & 2 \\ 1 & 1 & \end{array}$

232
2

2
1

2

1

1
1

2

1

1

12

1 


\section{Appendix 5}

Core considerations (market research checklists)-Patients.

\begin{tabular}{ll}
\hline Cluster & \multicolumn{1}{c}{ Core considerations } \\
\hline - What is the disease and cost burden and their distributions in target market: \\
diagnosed/undiagnosed, treated/untreated; in total, per stratum, per increment \\
(individual/intervention)? \\
target mapping \\
- What is the demographic/socioeconomic status of target population(s): (differentially) \\
affected strata, e.g. age brackets, ethnicity, affluency, geographic location? \\
\\
- Which patient cohorts benefit most from the product?
\end{tabular}

Level of medical literacy and awareness (low to high degree)

- Are patients aware of condition(s), the diagnostic and treatment spectrum, and of the risks associated with untreated condition leading to secondary condition/event?

- How independent are patients: self-/IT-assisted diagnosis/treatment; at home?

Disease and treatment journey (experience/behaviour)

- What is the lead-time from onset of disorder/symptoms to diagnosis and treatment; interim coping strategy (medical/non-medical)?

- Which are typical co-morbidities and mental health issues? Do patients suffer from disabilities and are they in pain?

- Which is the average number/frequency of interventions that the target population receives and what is their degree of treatment adherence? Are interventions convenient

Stakeholder decision drivers and tolerable (e.g. polypharmacy)?

- Are (all) of their symptoms controlled?

\section{Needs (im- and/or explicit)}

- Which are desired outcomes and treatment characteristics?

Price sensitivity (purchasing power and out of pocket burden)

- Typically, how many interventions do target population have to take and, importantly, pay for and what is the level of co-payment (OTC; prescription: no, partial, or full reimbursement)?

Behaviours and decision-points

- Do patients self-select products or seek advice from, e.g., pharmacists (OTC)?

- Which factors motivate providers/patients to switch medication or not (loyalty)?

- Which evidence/information is compelling to patients?

\section{Messaging}

- Which are the current narrative, concerns and language of patients around a disease/intervention?

Stakeholder

- How well do messages and promotion strategies (also of competitors) resonate with patients and providers?

engagement

\section{Advocacy groups}

- Do advocacy groups exist? If so, who are they, and which is their degree of activity and leverage (on those who they putatively represent)?

- Do they support or advocate against intervention? 


\section{Appendix 6}

Core considerations (market research checklists)_-Providers.

\begin{tabular}{|c|c|}
\hline Cluster & Core considerations \\
\hline $\begin{array}{l}\text { Stakeholders and } \\
\text { target mapping }\end{array}$ & $\begin{array}{l}\text { Landscape assessment (also professional societies) } \\
\text { - What is the quantity, distribution, and type of providers } \\
\text { and "influencers" in the market: KOLs, key specialties, } \\
\text { specialists, GPs, pharmacists, societies, etc. } \\
\text { - Which provider/HCP sees which type of patient and } \\
\text { how often? } \\
\text { Who are the early and late adopters, and how many are } \\
\text { there? } \\
\text { Which provider is consulted first for certain conditions: } \\
\text { GPs (gatekeepers) or pharmacists? Will new intervention } \\
\text { potentially require change of provider/care-giver? If so, } \\
\text { from whom to whom? } \\
\text { How many specialists exist in the care-pathway? } \\
\text { Who is the decision-maker/prescriber? }\end{array}$ \\
\hline
\end{tabular}

How high is the level of awareness (low to high degree)...

- Of condition(s), and diagnostic and treatment spectrum?

- Of potentially transferrable products in other specialties? E.g. specialty $B$ requests from manufacturer variant of product previously approved in specialty $\mathrm{A}$

Treatment experience/pathway

- Do interventions (also non-medical variants) exist? If so, what is the experience with them-for HCPs as well as patients?

- Do gaps exist in the medical care pathway?

Need/preferences/value fit

Stakeholder decision drivers

- Which is the unmet medical need in general and/or are there areas for improvement?

- How well will new product fit in(to) current pathway/existing infrastructure, i.e. degree of disruption?

- What is the degree of alignment between own product characteristics and HCPs preferences (e.g. test TPP)? What is the desired labelling, packaging, volume (pharmacists)

Decision points/prescribing behaviours

- Does professional resistance towards intervention exist, e.g. competing medical or non-medical alternatives (surgery), and/or negative/positive experience of HCPs with new product exist? If so, what is the potential impact on (prospective) adoption curve?

- Who prescribes which (competitor) product and how frequently, and is it in combination with other products?

- What are the prescription and recommendation drivers of providers (also vis-a-vis competitor product)?

\section{Evidence/messaging}

Stakeholder

- Which are the most meaningful endpoints and data, and medical plans and care pathways for HCPs?

engagement

- Which perceptions do HCPs have and which factors determine their degree of trust towards drug developers? 


\section{Appendix 7}

Core considerations (market research checklists) - NRAs.

\begin{tabular}{cc}
\hline Cluster & \multicolumn{1}{c}{ Core considerations } \\
\hline $\begin{array}{c}\text { Landscape assessment } \\
\text { target mapping }\end{array}$ & $\begin{array}{l}\text { Who are the regulatory bodies in target markets, } \\
\text { and for which remits and geographical jurisdictions } \\
\text { (national, regional, etc.) are they responsible? }\end{array}$ \\
\hline
\end{tabular}

\section{Priorities/awareness}

- Which diseases and unmet needs do regulators prioritise?

- Do they prefer specific types of interventions for an indication?

\section{Need/preferences (value-fit)}

- Which are the most meaningful safety and efficacy data in general (across regulators) and specifically (per regulator, e.g. data on domestic cohorts)?

- How can data collection be streamlined for requirements across regulators? E.g. by international trialling of intervention(s) in various domestic cohorts.

- Does own product conflict with other treatments?

- Are new methods of demonstrating safety/efficacy accepted (e.g. in silico modelling)?

Stakeholder decision drivers
- Are regulatory data requirements pre-determined by previous competitor applications (and approvals)?

Application/indications/label (decision points)

- Which are the likely indications at initial approval; which is the "cleanest" label possible?

- Which resource consumption (type and quantity of efficacy/safety data) will likely lead to a less or more restricted label (forecasting)?

- Which likely impact will different TPPs/labels have on uptake?

- Are providers using product out of indication and does data support the application for indication extension?

- Might post-launch data collection commitments change basis for cost assessment? Feeds into HTA for payers in next section.

- Are future changes to regulations (e.g. new hurdles) likely due to externalities and competitor products?

\section{Engagement/relationship}

- Has the value fit of TPP been tested and validated with

Stakeholder stakeholders in market (e.g. does intervention really address engagement unmet need or improve outcomes)? A TPP “endorsed” by physicians can considerably improve negotiations with regulators. 


\section{Appendix 8}

Core considerations (market research checklists)—Payers.

\begin{tabular}{cc}
\hline Cluster & \multicolumn{1}{c}{ Core considerations } \\
\hline $\begin{array}{c}\text { Stakeholders and } \\
\text { target mapping }\end{array}$ & $\begin{array}{l}\text { Landscape assessment (Payer-mix) } \\
\text { Are healthcare costs primarily financed/covered by public or private entities and who } \\
\text { specifically are the payers? Can be insurances, single-payers (e.g. government), } \\
\text { patients (out-of-pocket). }\end{array}$ \\
\hline
\end{tabular}

Priorities/awareness

- Are the political climate and economy stable?

- Which populations/disorders have been given priority status (e.g. minorities, age brackets, disease rarity, severity, EoL stages, etc.)?

- Are price moratoria in place and might there be funding delays (reimbursement)?

- What is overall cost of the disease?

Exclusivity/affordability

- Will step or incremental cost-increase be required to cover new intervention for indication/target population? Step increases considerably higher hurdle.

- Do new interventions fit into overall budget; which are the competing budgets of one entity; are existing alternatives already covered by budgets of different entity?

- Which buying mechanisms/arrangements exist in the market? E.g. for hospitals/buying consortia: bundled payments, exclusive basket of drugs per manufacturer, etc.

\section{Need/preferences (value-fit)}

- Does intervention provide step improvement regarding (cost-)effectiveness?-Increasingly required for branded products; downward price pressures compelling payers to prefer generics. Is it possible to demonstrate short- and/or long-term benefit/ROI for payer?

Stakeholder decision drivers
- Are payers requiring milestone-based reimbursement/payment models for e.g. novel staged interventions, such as genetic therapies?

- Which are the most meaningful efficacy and cost data points overall? Post-launch: effectiveness data sourced in phase 4 clinical trials.

- What are the incremental costs for specific levels of effectiveness?

HTA/formulary status/reimbursement (decision-points)

- As HTA is key to formulary listing and pricing/reimbursement level: which are essential cost-effectiveness data, is the payer perspective (society, health system), and are the parameters/weightings used in market.

- Which is the likely formulary status (outcome of HTA) and thus reimbursement level?

- Are complementary products/services, e.g. companion diagnostics, covered, too?

- How might the regulatory label impact on HTA? E.g. indication, target population, dosing, etc.

- Has the formulary status been "pre-negotiated” by previous HTAs? -Will determine data requirements.

- Has variation across countries/jurisdictions been taken into account?-E.g. evidence requirements, reimbursement levels, forecasting worst/best case

- Which impact might patient advocacy groups have on payers and prices?

- Use similar technologies for HTA if no direct comparator exists (if applicable, also those already introduced in other specialties).

Stakeholder

engagement

\section{Relationships}

- Has a relationship with payers been established and if so, how good is the relationship? 


\section{Appendix 9}

Core considerations (market research checklists)—Competitors.

\begin{tabular}{|c|c|}
\hline Cluster & Core considerations \\
\hline $\begin{array}{l}\text { Stakeholders and } \\
\text { target mapping }\end{array}$ & $\begin{array}{l}\text { Landscape assessment } \\
\text { (in particular status quo and future scenarios) } \\
\text { - Who (competitor) is/will be introducing which product, } \\
\text { in which market (segment), and when? } \\
\text { - Who (provider) is using which product, in which } \\
\text { therapeutic area and how (e.g. in combination)? } \\
\text { - What are the sales volumes per product } \\
\text { (or combination thereof)? }\end{array}$ \\
\hline
\end{tabular}

Product exclusivity

- Will own product be 1 st/2nd... to market?

- Does the market provide IP protection, is it enforced and for how long?

- Will IP protection of competing (branded) product expire soon?

- Are relevant markets contractual, i.e. do competitors have exclusive arrangements?

Market share/sales force

- Is pertinent market dominated by a competitor, saturated or highly specialised (niched)?

- What is the formulary and reimbursement status of competing product?

- How are budgets allocated to existing products? How high are allocations?

Stakeholder

- What are the sales activities (area and representatives) of competitors?

decision drivers

- How might a competitor react to the launch of a new (competing) product?

\section{Customer experience}

- What are the advantages and disadvantages of competitor products; what can be improved?

Positioning/pricing/pipelines (decision points)

- How have competitors positioned, i.e. matched with and "pitched"/communicated the value fit of their products in therapeutic area and specialties?

- Does competitor focus on private or reimbursement market(s)? If on both, what is the sequence?

- What is their pricing model (e.g. tiered-/value-based-pricing?

- What is the likely launch date of new products and what is the potential competitive advantage?

Messaging

- How do competitors engage with customers and how well

Stakeholder do their strategies resonate with them?

engagement

\section{Relationships/reputation}

- How good is the relationship of competitors with providers ("historical" preference)? 


\section{Appendix 10}

Dissemination of Market Intelligence.

\begin{tabular}{c}
\hline Considerations \\
\hline Awareness
\end{tabular}

- Is MI used by individuals on a daily basis? If not, the likelihood is high that it will not be recalled (correctly).

- Is access to MI straightforward and easy, e.g. via, IT/databases, dedicated individuals?

- Does a pitch of current project and MI to inform/convince others/superiors exist?

$$
\text { Targets }
$$

- Is detailed MI primarily provided to franchise heads/development leads-on a need to know basis, for alignment purposes-or distributed to all relevant personnel?

- Do multidisciplinary teams develop TPPs together? If so, this can improve MI dissemination.

\section{Timepoint}

- Are regular (global) meetings within and across functions held to improve the dissemination and interpretation of MI?

- Is subsidiary: head-office: subsidiary exchange of more general (not necessarily market specific) MI frequent? This can improve MI alignment, and complement and validate existing MI.

- Are meetings held before regulatory application? This facilitates discussion, interpretation and collation of relevant MI.

\section{Mode}

- Is the presentation of MI unbiased, succinct and actionable?

- Is MI governed across stages of development and teams? Development leads change over time. Without adequate governance, important information can be lost or difficult to retrieve in a timely manner.

\section{Appendix 11}

Responsiveness to Market Intelligence.

\section{Considerations}

\section{Data management}

- Is data collection seized once sufficient data are available to take (specific) decisions, in order to not further tax resources that could be better used elsewhere?

- Are data collection instruments co-created with and streamlined to the needs of those using them, e.g. HCPs?

- When out-licensing product or selling company: has proper market research been performed to have a good value proposition and be taken seriously?

\section{Development/launch strategy/marketing plan}

- Are there any out-licensing opportunities for new indications identified during trials that are too expensive to pursue?

- Is it possible to change development strategy if MI indicates that competition is developing a similar or superior product, or advocacy groups will frustrate uptake?

- Has the know-how of subsidiaries/head office been considered and assessed for its exploitation potential? Other entities can have substantial experience with products/MI generation in other markets. 
Label/indications

- Pre-launch and during clinical trials: have possibilities of extending the indication or switching to others, if initial indication(s) prove(s) unfeasible, been explored?

- Post-launch: is the potential extension to other indications continuously assessed (e.g. if benefit in other patients/cohorts has been demonstrated)?

- Does the regulatory label sufficiently differentiate own products from those of competitors?

Product (pre-launch)

- Have alternatives pertinent to the dosing, appearance, storage requirements, etc., of a product, been assessed?

- Is a quarterly development plan/the TPP maintained and updated?

Product (post-launch)

- Have post-launch modifications of product pertinent to the formulation, mode of delivery, safety features, quantity of product in packet, etc. been thoroughly assessed?

Positioning/internal \& external promotion

- If novel methods of promotion/advertisement are used: have they been backed up by rigorous analysis?

- Has the market been primed by e.g. involving KOLs in product development, shaping and positioning?

- Once self-select customers identified (OTC): have advertisement campaigns been adapted to reflect customer wishes (superior effectiveness, convenience, etc.), and have pharmacists (proxy targets) been provided with compelling evidence.

- Have product messages and their presentation been tested and adapted to resonate with customers? This refers to health claims or alternative benefits (e.g. reducing side effects) for patients/providers.

- Have changes in decision makers, such as from HCPs to patients, e.g. if patients are highly medically literate, been considered?

- Has promotional material/advertisement been designed for/adapted to patient narrative, topics of concern, language (e.g. social media)?

\section{Appendix 12}

Study-relevant components of the market orientation framework.

\section{Generation of market intelligence}

According to the MO framework, MI "is a broader concept than customers' verbalized needs and preferences in that it includes an analysis of exogenous factors that influence those needs and preferences."[19, p.4] First, it is essential for an organisation to understand who specifically their customers are-in healthcare markets, e.g., buyers (prescribers/healthcare providers), payers (health insurances/funds), and consumers (patients) [48]. In addition to understanding customers' current preferences, an important function of MI is to anticipate customers' future needs. According to MO, the most prominent examples of exogenous factors are: the regulatory (and policy) environment, existing and prospective technology, competitor activities, and the dynamics of, and changes in, the industries/environments of customers [19]. 
The generation of MI is facilitated by various collection, analysis and synthesis methods: analysis of quantitative data using statistical methods and modelling is frequently used to gauge e.g. the size of the market, the potential of developing a feasible product, whereas qualitative but also mixed-methods approaches, such as questionnaire- and interview-based research, are used to identify motivations and preferences that lead to behaviours of customers, and thus estimate their potential to adopt, or switch to, a prospective product [19].

\section{Dissemination of $M I$}

According to $\mathrm{MO}$, a necessary pre-requisite to facilitating proper, i.e. coordinated and cross-functional, responsiveness of an organisation to MI is its dissemination across the entire organisation. Ideally, all departments and individuals generate and disseminate intelligence to, and receive intelligence from, one another. This can include particular effort on behalf of one department to convince key individuals or other departments of the relevance of "their" intelligence. Regular meetings between various departments, pre-defined information dissemination routes across and within departments, as well as regular internal newsletters can be considered formal, proactive mechanisms of dissemination. "Hall-talk" and the establishment of central repositories containing market data, and customer needs and characteristics conveyed e.g. through story-telling notes, can be powerful informal, passive dissemination tools, the value of which, according to K\&J, should not be underestimated [19].

Responsiveness to $M I$

Finally, responsiveness activities might include the selection or re-selection and priming of target markets, and adapting development and product characteristics, services, distributions channels, and promotion strategies. Regarding marketing authorisation (regulatory approval) and market access (formulary listing and reimbursement), activities will at the very least include the collection, analysis and presentation of pertinent MI and the coordination of the regulatory, medical affairs and sales departments to facilitate concerted responses to newest intelligence, and ensure non-conflicting communication with relevant agencies in target market(s) [19].

\section{Appendix 13}

Working definitions

Patients

"Individuals participating in the health care system for the purpose of receiving therapeutic, diagnostic, or preventive procedures." (Source: Pubmed)

Providers

"A licensed person or organization that provides healthcare services." (Source: $\mathrm{NCI})$

National regulatory agencies (NRAs)

"NRAs are national regulatory agencies responsible for ensuring that products released for public distribution (normally pharmaceuticals and biological prod- 
ucts, such as vaccines) are evaluated properly and meet international standards of quality and safety." (Source: WHO)

Payers

Payers are any entity that covers the cost of healthcare utilisation, and can range from public payers such as, for example, sickness funds (in social health insurance systems) or government institutions (single payer systems) or, private parties, such as insurances, individuals. (Source: JKT)

Competitors (Competition)

"Competition is an activity involving two or more firms, in which each firm tries to get people to buy its own goods in preference to the other firms' goods." (Source: Collins Dictionary) 